\title{
Recycled Aggregates for Concrete: Problems and Possible Solutions
}

\section{Enric Vázquez}

Universitat Politecnica de Catalunya, Constructing Cycle S.L., C/Bertran 123, atico 1'a, 08023 Barcelona, Spain

\section{Abstract}

Reducing the use of natural resources and replacing it with waste material to avoid problematic landfills has been the principal focus of an emerging and important recycling market in most developed countries. Crushed concrete and masonry waste can be suitable for replacing coarse aggregate in concrete. When crushed masonry is used, compressive strength is lower and the material's high porosity affects durability and shrinkage. With crushed concrete aggregate the compressive strength and durability depend on the quantity of attached mortar, which is responsible for higher porosity, weak zones in the aggregate, and is also related to the new concrete durability. Smart crushers liberate more adhered mortar and could provide a good solution.

Methods to guarantee the quality of production are applied, but in homogeneity of the concrete waste of different origins continues to inspire distrust in many consumers, who continue to prefer the use of sub base material in roads. Irregularity of the distribution of chlorides or other contaminants makes the quality control a complicated process, but combined analysis of durability and sustainability as well as the use of indicators and models can be a solution. In situ recycling with only one origin of concrete can assure homogeneity.

Many research papers imply the need of using more cement to compensate for the differences in properties compared to concrete with primary aggregates.

\section{Recycled Aggregates in Concrete: Closing the Cycle}

The recycling of construction and demolition waste (CDW) emerged later than recycling of other types of materials, such as metals. This was influenced by different factors, many of them related to economy and the great availability of natural aggregates in many countries, like Spain. After the Second World War, CDW processed as aggregates was used as sub base for roads and in concretes of low quality. In countries like Germany and England the quantities of rubble left from the war and the demolitions produced in the reconstruction of cities, promoted a large scale use of aggregates of mixed composition. From the information published in research papers 20 years later, we observe that in the first decade after the war, Germany used 12 million $\mathrm{m}^{3}$ of masonry aggregates in concrete. These aggregates were produced starting from rubble. In the Netherlands, for example, the problems produced by the accumulation of waste coincided with the environmental difficulties of extracting gravel and sand, stimulating the use of CDW. Other developed countries, such as Japan, followed more or less the same tendencies.

In the 1970s, real systematic research began in laboratories and demonstration projects exploring the utilization of CDW in construction works. In 1978, Nixon PJ published Recycled Concrete as an Aggregate for Concrete - A review [1]. In 1988 Schulz, R.R. [2] concluded in his presentation in the $2^{\text {nd }}$ RILEM Symposium about Reuse of Demolition Waste: "If recycling building materials is regarded as a closed loop system, all valuable constituents in the waste may not be dissipated by applications of secondary importance (e.g. land fill). As far as it can be afforded from an economical point of view, processed rubble should be employed on the highest possible level of utilisation. The reuse of building wasteas aggregate for concrete seems to be especially prosperous and may be regarded as the highest level of refining."

Others suggested directly using the concrete fraction as aggregate in structural concrete for maximum value up cycling. For many years the initial tendency to use the recycled aggregates in road sub bases (down cycling) has predominated in all countries, however the replacement of natural aggregates by a limited quantity of recycle concrete aggregates in structural concrete is today a common practice in those countries that have limited natural aggregate resources.

\section{Properties of Concrete with Recycled Aggregates}

The predominant volumes of CDW in most countries are of mixed composition, consisting of masonry elements, concrete granulates and sand. The treatment of these waste materials can produce very easily mixed recycled aggregates. When aggregates of ceramic origin are used in the new concrete, the compressive strength and elastic modulus will be lower compared with the results obtained using natural aggregates. A higher porosity and important change in the pore structure of the concrete will influence all physical properties and especially the durability of the concrete.

In a study conducted at UPC (Universitat Politecnica de Catalunya), which evaluated the influence of using recycled aggregates $>4 \mathrm{~mm}$ on the properties of concrete [3], it was observed that for HRC (recycled concrete with ceramic aggregate), using 20\%, 50\% and 100\% of substitution with ceramic recycled aggregate, the porosity of the concrete increased $15,99 \%, 20,1 \%$ and $20,63 \%$, respectively. When preparing $\mathrm{HRH}$ (recycled concrete with concrete aggregate)with $20 \%$, $50 \%$ and $100 \%$ of recycled concrete coarse aggregate $>4 \mathrm{~mm}$ and with the same quantity of fresh mortar, very low increase of the mercury intrusion porosity was observed for up to $50 \%$ of substitution $(11.09 \%$ to $12.11 \%)$.

"Corresponding Author: Prof. Enric Vázquez, Universitat Politecnica de Catalunya, Constructing Cycle S.L., C/Bertran 123,atico 1a, 08023 Barcelona, Spain; E-mail: enric.vazquez@upc.edu

Citation: Vázquez E (2016) Recycled Aggregates for Concrete: Problems and Possible Solutions. Int J Earth Environ Sci 1: 122. doi: https://doi. org/10.15344/2456-351X/2016/122

Copyright: @ 2016 Vázquez. This is an open-access article distributed under the terms of the Creative Commons Attribution License, which permits unrestricted use, distribution, and reproduction in any medium, provided the original author and source are credited. 
Citation: Vázquez E (2016) Recycled Aggregates for Concrete: Problems and Possible Solutions. Int J Earth Environ Sci 1: 122. doi: https://doi.org/10.15344/2456$351 \mathrm{X} / 2016 / 122$

Page 2 of 5

In the case of $\mathrm{HRH}$, the important change only appeared with the presence of $100 \%$ of coarse recycled concrete aggregate $>4 \mathrm{~mm}$ $(18.78 \%)$. In this case a limitation in the quantity of recycled aggregate is necessary. The porosity is mostly determined by the porosity of the old mortar attached to the recycled concrete aggregates, and the quality of the recycled aggregate depend of the quantity and homogeneity of this attached mortar (Figure 1).
The mean diameter of the poresin the concrete with recycled concrete aggregate is $0.08 \mu \mathrm{m}$ (figure $2, \mathrm{HRH}$ ). In the concrete with recycled ceramic aggregate two peaks are observed, the first at a diameter of $0.08 \mu \mathrm{m}$ and the second at $1.3 \mu \mathrm{m}$. (figure $3 \mathrm{HRC}$ ). Not only can we observe more porosity, but a difference in pore diameter and its distribution can be seen, which will influence the permeability, the absorption and the durability of the concrete.

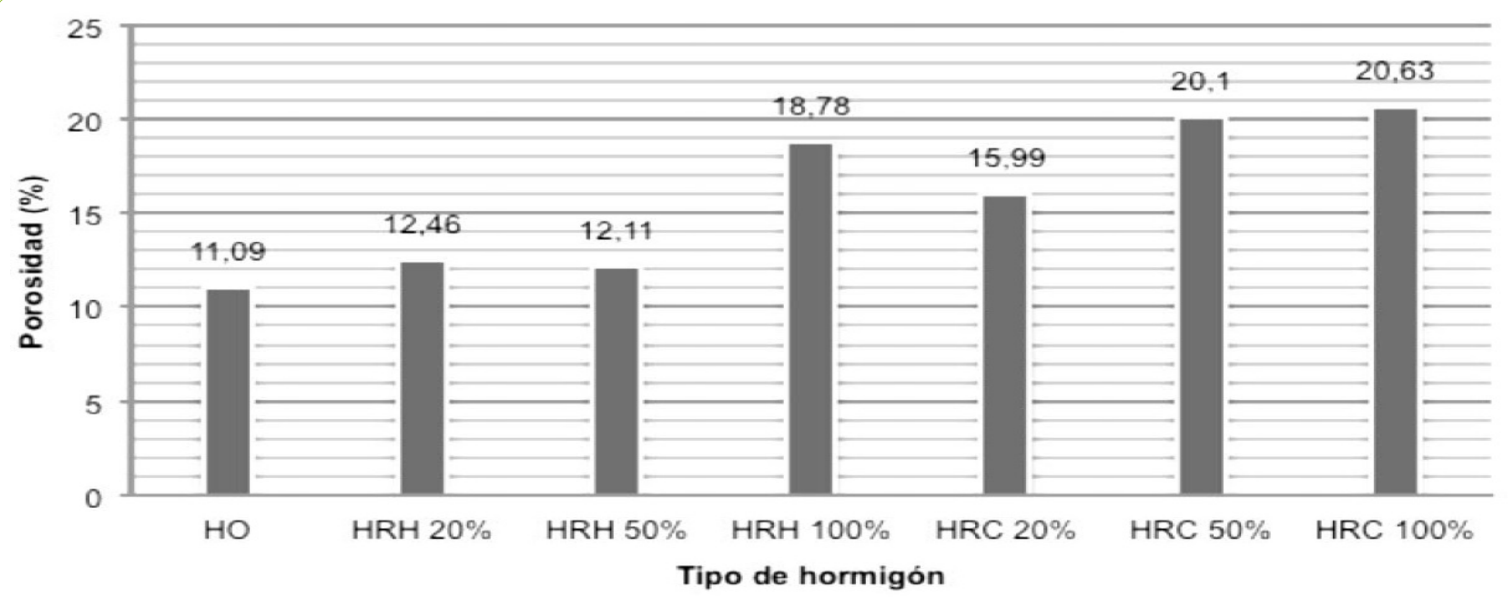

Figure 1: Mercury Intrusion Porosity of Recycled Concrete with Recycled Concrete Aggregate (HRH) and with Ceramic Recycled Aggregate (HRC).

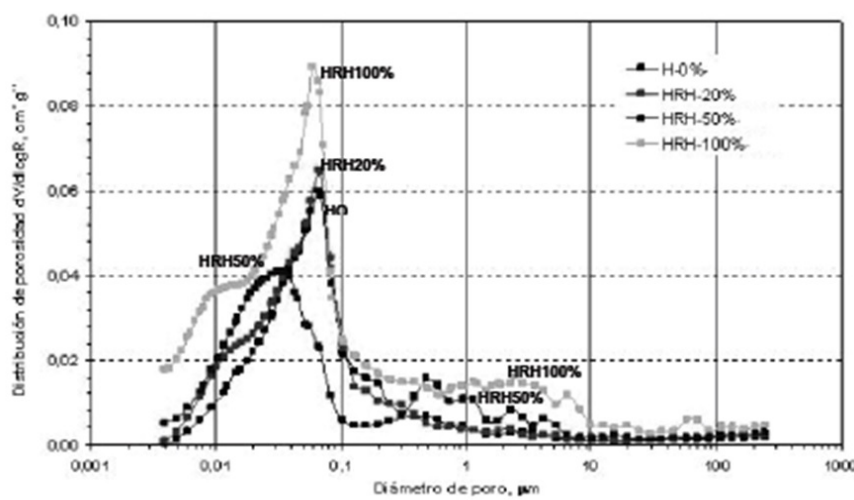

Figure 2: Mercury Intrusion Porosity of Recycled Aggregate with Concrete Recycled Aggregate (HRC).

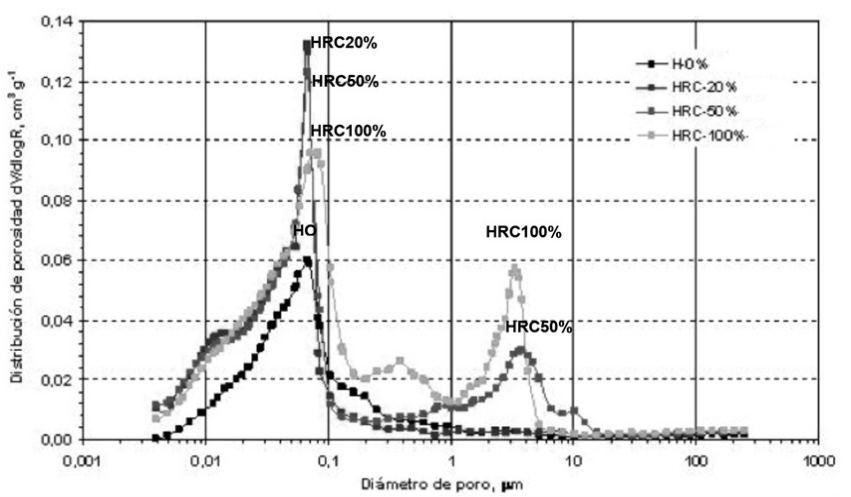

Figure 3: Mercury Intrusion Porosity of Recycled Aggregate with Ceramic Recycled Aggregate (HRC).
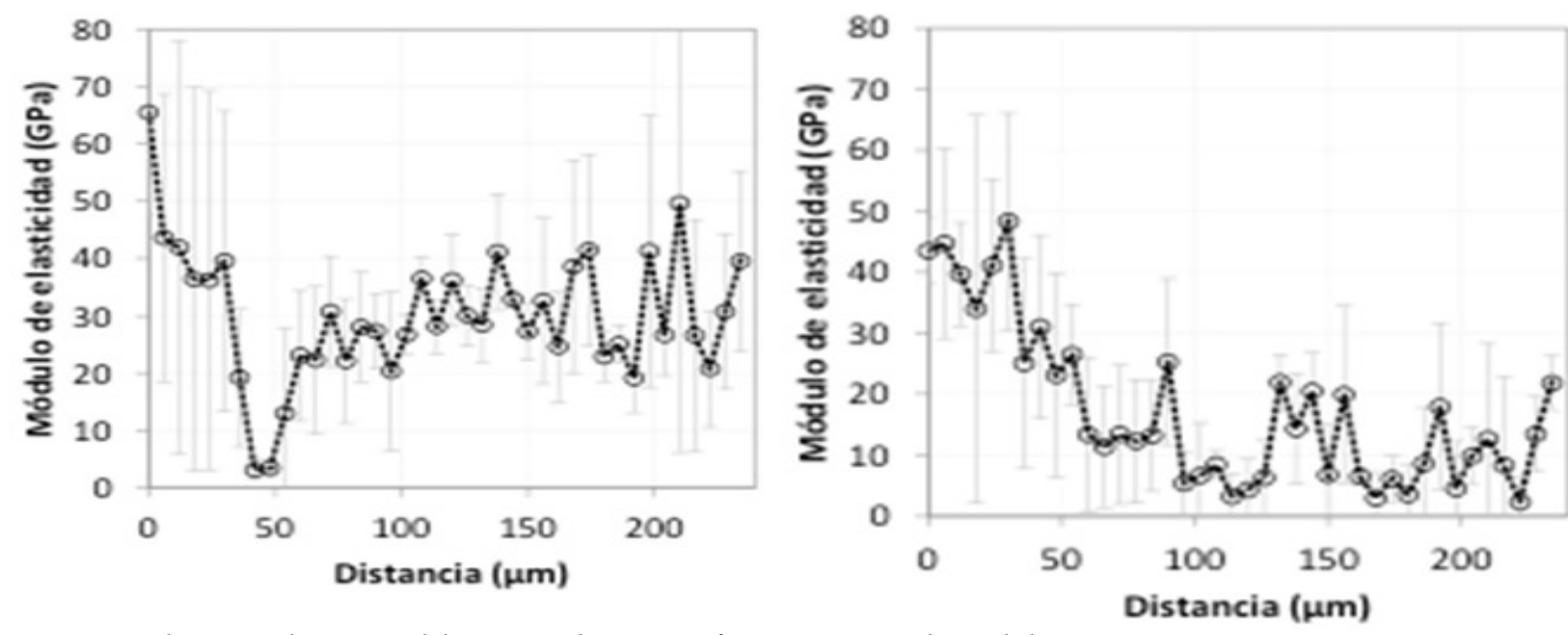

Figure 4: Nano indentation. Elasticity Modulus versus distance in reference concrete and Recycled Ceramic Aggregate Concrete.

Int J Earth Environ Sci

ISSN: 2456-351X
IJEES, an open access journal Volume 1. 2016. 122 
In the study of the Interfacial Transition Zone aggregate paste by Sidorova et al. [4], the Nano indentation analysis in the case of the ceramic aggregate could not detect the formation of a different zone, according to the rest of the cement paste. The very high porosity of the ceramic aggregates caused that absorption of water from the paste and the accumulation of water near the aggregate, as is the case when an interfacial transition zone is formed, could not exist. All the paste had a weaker elasticity modulus compared to the concrete with only natural aggregate or recycled concrete aggregate (figure 4 and Figure $5)$.

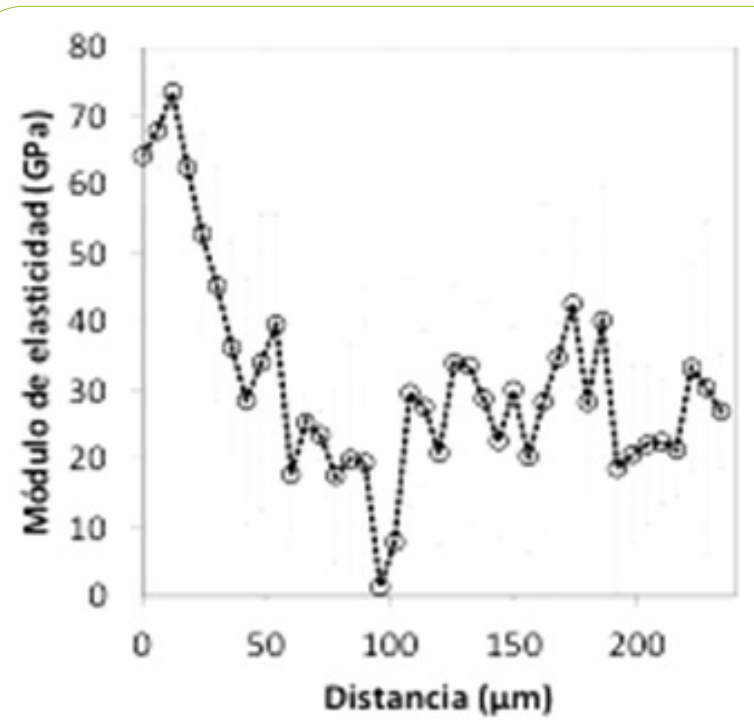

Figure 5: Nano indentation. Elasticity Modulus versus distance in Recycled Concrete with Recycled Concrete Aggregate.

\section{Durability of Recycled Concrete}

Many researchers have studied the influence of attached mortar and its content on the properties of recycled concrete aggregate. Attached mortar is the weak point from the mechanical point of view (Figure 6). Using only the coarse fraction ( $>4 \mathrm{~mm}$ ) from concrete aggregate, in proportions of substitution of the natural gravel under $50 \%$ and with an adequate quality control, results in minor differences.

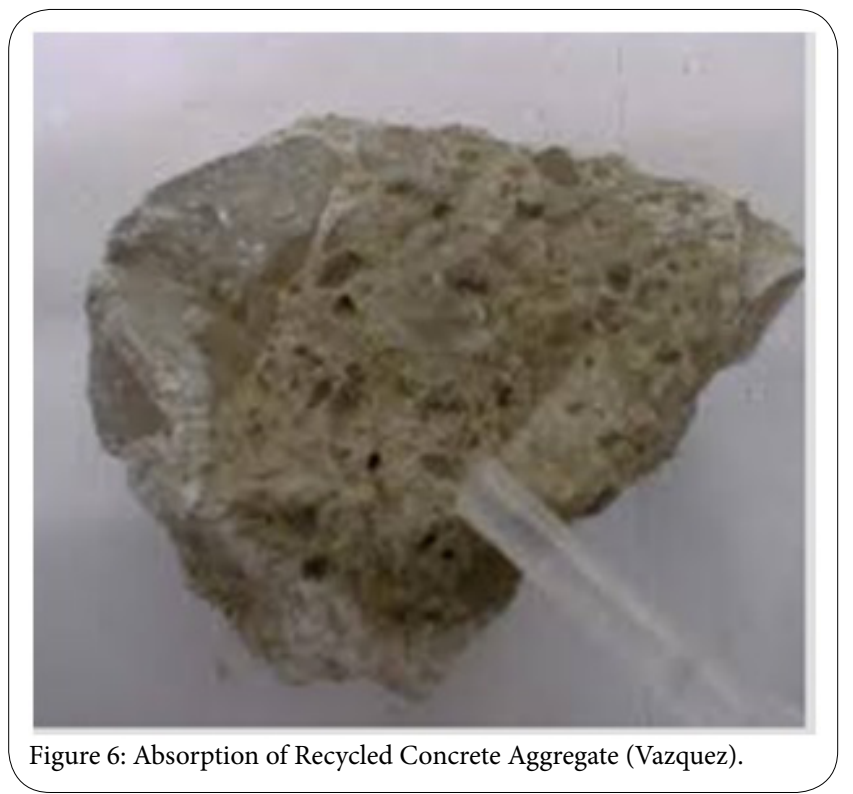

Some doubts subsist regarding the durability and shrinkage of the recycled concrete. Recycled concrete with substitutions of natural gravel by $30-50 \%$ can present greater long-term shrinkage and creep, depending on the quantity and diameter of the pores of the recycled aggregates as well as on the quantity of cement added.

The resistance to chemical attacks and the frost resistance will depend, as in all kind of concrete, on the water and aggressive solutions penetration. The increase in porosity will influence penetration and diffusion mechanisms. The combination of frost and the use of deicing salts will be very dangerous for recycled concretes with concrete aggregates with high porosity.

Villagran et al. [5] observed that the substitution of natural gravel by recycled concrete aggregates caused opposed effects. Due to the higher porosity of the aggregate the chloride penetration rate was increased, whilethe attached mortar induced the chloride binding capacity.

Vazquez E et al. [6] confirmed the improvement of the binding capacity. Chloride binding in concrete results due to a chemical reaction between chlorides and hydrated cement aluminates as well as due to the physic-chemical adsorption in the CSH (Calcium Silicate Hydrate). Friedel's salt formation was detected and the chloride binding in a CSH plaque was verified. High-recycled aggregate content led to an improvement in durability of concrete with sufficiently low $\mathrm{w} / \mathrm{c}$ ratio, in terms of chlorides presence. The reinforcement was less affected. If other deleterious components that can attack or compete with the Friedel's salt and liberate the retained chlorides exist, the increase in durability disappears.

\section{Sustainable Solutions}

Durability is a determinant factor in the sustainability. Varela et al. [3] produced concretes with different $\%$ of recycled concrete aggregate $>4 \mathrm{~mm}$ and a reference concrete with natural aggregate and the same $\mathrm{w} / \mathrm{c}$. The diffusion coefficient $\mathrm{D}$ is a chloride parameter considered useful in evaluating the transport of chloride ion in concrete. Using the experimental values obtained in the laboratory the service life was calculated with different models. Compared with the reference concrete, the concrete with $20 \%$ recycled concrete aggregate had similar service life values. The author proposed the use of Durability Indicators based on the calculated service life for the chloride penetration, and the total service life as a solution, to evaluate sustainability based on the durability of a recycled concrete. Conceptually the idea seems promising, however it requires further research.

One radical solution could be the use of soft crushers that can separate an important quantity of the attached mortar. In this case it would be important to find application for the fines produced, with the use in special cement production being an interesting possibility.

Some researchers accept the addition of more cement compared to the reference concrete with natural gravel.

More cement compensates the loss in compressive strength and reduces the paste permeability, consequently increasing the durability. Applying LCA in each case will establish if the increase in $\mathrm{CO}_{2}$ related with the production of cement is environmentally acceptable.

Kong et al. [7] had developed a triple mixing method to realize surface coating of the recycled concrete aggregate with pozzolanic 
materials. The results of the study revealed that in the coated particles the pozzol an can react with calcium hydroxide crystals present on the surface, as well as in the pores near the surface, of the recycled aggregate, improving the strength and durability of the interfacial transition zone and positively influencing the properties of the new concrete.

Shi-Cong Kou et al. [8] incorporated different mineral admixtures including silica fume, meta kaolin, fly ash and GGBS (Ground Granulated Blast Furnace Slag). Silica fume and meta kaolin contributed to short and long term properties and the other two improved the durability but decreased the compressive strength when the replacement of cement was of $35 \%$ and $55 \%$, respectively.

Seidemann et al. [9] are publishing a very promising research from the environmental point of view, which suggests carbonating the recycled aggregate with $\mathrm{CO}_{2}$ that originates from industrial activities. The result would be the reinforcement of the attached mortar and the reduction of its permeability.

Angulo et al. [10] have checked the plus of cement often proposed to produce high performance concrete with recycled aggregate and proved the negative result in LCA.

Fathifazl et al. [11] proposed a new mix design method called EMV (Equivalent Mortar Volume). Conventional Mix Design treats the recycled aggregate as one phase material, as one aggregate. The result is an excessive quantity of mortar, with attached mortar plus fresh mortar being added. In the EMV method, the two phases, aggregate and attached mortar, are considered as separate phases. The results of applying this new method demonstrated that $24 \%$ of cement could be saved compared to the results of the ACI method. The EMV method reduced slump. The use of air entraining admixtures partially solved the problems related with workability in fresh state, only lowering the plastic viscosity.

Jimenez et al. [12] adapted the EMV method to the Bolomey method, which is more often used in Europe, resulting in $8 \%$ reduction in cement, while obtaining equivalent durability and strength [13]. Jimenez used air entrainer that reduced the plastic viscosity, and super plasticizer in high dosages that decreased the yield strength value.

Jimenez et al. [14] environmentally evaluated three design methods using the LCA Methodology (CML)from the Leiden University. The EMV method in the two versions (12 and13) accomplished better environmental performances than the conventional methods for the design of recycled concrete. Cement is, by far, the most influencing material in most impact categories of the studied concretes in terms of its released emissions.

After cement, natural aggregates and facilities are the most significant contributors to the majority of impact categories.

Chemical admixture emissions influence is rather small.

\section{Conclusion}

To recycled concrete with structural application is practically an obligation if we want to close the cycle, however, only a few countries, such as the Netherlands, have applied a well-established practice.
When aggregates of ceramic origin are used in the new concrete, the compressive strength and elastic modulus will be lower compared with the results obtained using natural aggregates. With the very high porosity of the ceramic aggregates caused that absorption of water from the paste and the accumulation of water near the aggregate, as is the case, an interfacial transition zone can not exist. All the paste has a weaker elasticity modulus compared to the concrete with only natural aggregate or recycled concrete aggregate. The use of ceramic recycled aggregates in structural concrete must be avoided in our opinion and experience.

The substitution of $100 \%$ of the natural aggregates $>4 \mathrm{~mm}$ is possible, but depending of the porosity of the attached mortar in the recycled concrete aggregate an important decrease of the strength and elastic modulus of the new concrete can appear.

Recycled concrete aggregates can improve the retention of chlorides. Chloride binding in concrete results due to a chemical reaction between chlorides and hydrated cement aluminates as well as due to the physic-chemical adsorption in the CSH. In this case the durability of concrete can be improved when at the same time we have a sufficiently low $\mathrm{w} / \mathrm{c}$ ratio.

The use of more cement then in the reference concrete to compensate the loss in compressive strength present in some recycled concretes is not sustainable. Applying LCA in each case of study will establish if the $\mathrm{CO}_{2}$ related with the quantity of cement used is environmentally acceptable. The mix design method called EMV (Equivalent Mortar Volume) proposed by Faityfathl and others, extended by Jimenez and others, can be a sustainable solution to use less cement and assure the durability and strength of the recycled concrete. The use of super plasticizers and air entraining admixtures can be a good solution to guarantee the workability of these concretes.

The use of fly ash and other mineral admixtures in recycled concretes helps to reduce the cement content.

If we want to extend the use of recycled concretes, we have to apply environmentally sustainable solutions that can produce materials that are competitive not only in strength but also in durability with the normal concrete with only natural aggregates.

\section{Competing Interests}

The authors declare that they have no competing interests.

\section{References}

1. Nixon PJ (1978) Recycled concrete as aggregate for concrete-a review. Matériaux et Constructions 11: 371.

2. Schulz RR (1988) Concrete with recycled rubble - Developments in West Germany. RILEM Reuse of Demolition Waste 2: 508.

3. Varela E (2012) Evaluación de la sostenibilidad ambiental de hormigones con áridos reciclados procedentes de RCD, PhD. Thesis, UPC.

4. Sidorova A, Vazquez E, Barra M, Roa JJ, Jiménez E (2014) Study of the recycled aggregates nature's influence on the aggregate-cement paste interface and ITZ. Construction and Building Materials 68: 677-684.

5. Villagran-ZaccardiY, Zega C, Di Maio A (2008) Chloride Penetration and Binding in Recycled Concrete. J Mater Civ Eng 20: 449-455.

6. Vazquez E, Barra M, Aponte D, Jimenez C, Valls S (2014) Improvement of the durability of concrete with recycled aggregates in chloride exposed environment. Construction and Building Materials 67: 61-67. 
Citation: Vázquez E (2016) Recycled Aggregates for Concrete: Problems and Possible Solutions. Int J Earth Environ Sci 1: 122. doi: https://doi.org/10.15344/2456$351 X / 2016 / 122$

Page 5 of 5

7. Kong D, Ting L, Tianjin Z, Chengchang M, Jun J, et al. (2009) Effect and Mechanism of surface coating pozzolanics materials around aggregate on properties and ITZ microstructure of recycled aggregate concrete. Construction and Building Materials 24: 701-708.

8. Kou SC, Poon CS, Agrela F (2011) Comparisons of natural and recycled aggregate concretes prepared with the addition of different mineral admixtures. Cement and Concrete Composites 33: 788-795.

9. Seidemann M, Müller A, Ludwig HM (2015) Changes of the material properties by selective carbonation of recycled aggregates from concrete Proceedings of Progress of Recycling in the built environment, Sao Paulo.

10. Angulo SC, John Ulsen C, Kahn H, Müller A (2013) Separação óptica do material cerâmico dos agregados mistos de resíduos de construção e demolição. Ambient Constr 13: 2.

11. Fathifazl G, Abbas A, Razagpur AG, Isgor OB, Fournier B, et al. (2009) New Mixture Proportioning Method for Concrete Made with Coarse Recycled Concrete Aggregate. J Mater Civ Eng 21: 601-611.

12. Jiménez C, Barra M, Valls S, Aponte D, Vazquez E (2013) Equivalent Mortar Volume 16 (EMV) method for proportioning recycled aggregate concrete: Validation under the Spanish context and its adaptation to Bolomey methodology for concrete proportioning. Materiales de Construcción 63: 311.

13. Faleschini F, Jimenez C, Barra M, Aponte D, Vazquez E, et al. (2014) Rheology of fresh concretes with recycled aggregates. Construction and Building Materials 73

14. Jimenez C, Barra M, Josa A, Valls S (2015) LCA of recycled and conventional concretes designed using the Equivalent Mortar Volume and classic methods. Construction \& building materials 84: 245-252. 